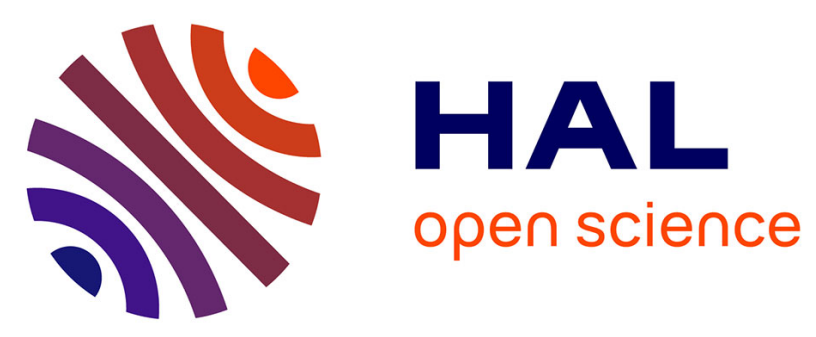

\title{
Radiographic Outcomes of Adult Spinal Deformity Correction: A Critical Analysis of Variability and Failures Across Deformity Patterns
}

Bertrand Moal, Frank Schwab, Christopher P. Ames, Justin S. Smith, Devon Ryan, Praveen V. Mummaneni, Gregory M. Mundis Jr, Jamie S. Terran, Eric Klineberg, Robert A. Hart, et al.

\section{To cite this version:}

Bertrand Moal, Frank Schwab, Christopher P. Ames, Justin S. Smith, Devon Ryan, et al.. Radiographic Outcomes of Adult Spinal Deformity Correction: A Critical Analysis of Variability and Failures Across Deformity Patterns. Spine Deformity, 2014, 2, pp.219-225. 10.1016/j.jspd.2014.01.003 . hal-01086753

\section{HAL Id: hal-01086753 https://hal.science/hal-01086753}

Submitted on 13 Feb 2015

HAL is a multi-disciplinary open access archive for the deposit and dissemination of scientific research documents, whether they are published or not. The documents may come from teaching and research institutions in France or abroad, or from public or private research centers.
L'archive ouverte pluridisciplinaire $\mathbf{H A L}$, est destinée au dépôt et à la diffusion de documents scientifiques de niveau recherche, publiés ou non, émanant des établissements d'enseignement et de recherche français ou étrangers, des laboratoires publics ou privés. 


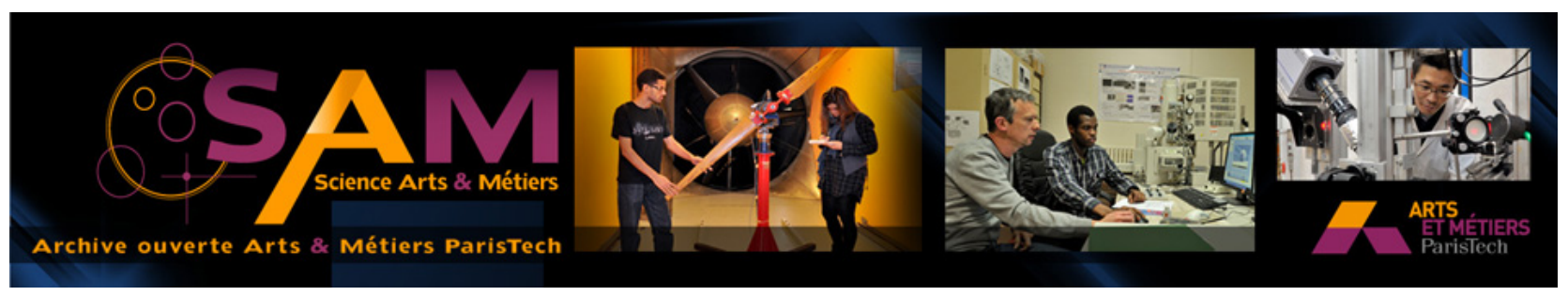

\section{Science Arts \& Métiers (SAM)}

is an open access repository that collects the work of Arts et Métiers ParisTech researchers and makes it freely available over the web where possible.

This is an author-deposited version published in: http://sam.ensam.eu

Handle ID: .http://hdl.handle.net/10985/8975

\section{To cite this version :}

Bertrand MOAL, Franck SCHWAB, Christopher AMES, Justin SMITH, Devon RYAN, Mummaneni PRAVEEN, Jamie TERRAN, Eric KLINEBERG, Robert HART, Boachie-Adjei OHENEBA, Christopher SHAFFREY, Wafa SKALLI, Virginie LAFAGE - Radiographic Outcomes of Adult Spinal Deformity Correction : A Critical Analysis of Variability and Failures Across Deformity Patterns - Spine Deformity n`2, p.219-225 - 2014 


\title{
Radiographic Outcomes of Adult Spinal Deformity Correction: A Critical Analysis of Variability and Failures Across Deformity Patterns
}

\author{
Bertrand Moal, MS ${ }^{\mathrm{a}, \mathrm{h}}$, Frank Schwab, MD ${ }^{\mathrm{a}}$, Christopher P. Ames, MD ${ }^{\mathrm{b}}$, \\ Justin S. Smith, MD, $\mathrm{PhD}^{\mathrm{c}}$, Devon Ryan, MS ${ }^{\mathrm{a}}$, Praveen V. Mummaneni, $\mathrm{MD}^{\mathrm{b}}$, \\ Gregory M. Mundis, Jr, MD ${ }^{\mathrm{d}}$, Jamie S. Terran, BS ${ }^{\mathrm{a}}$, Eric Klineberg, MD ${ }^{\mathrm{e}}$, Robert A. Hart, MD ${ }^{\mathrm{f}}$, \\ Oheneba Boachie-Adjei, MD ${ }^{\mathrm{g}}$, Christopher I. Shaffrey, $\mathrm{MD}^{\mathrm{c}}$, Wafa Skalli, $\mathrm{PhD}^{\mathrm{h}}$, \\ Virginie Lafage, $\mathrm{PhD}^{\mathrm{a}}{ }^{*}$, International Spine Study Group \\ ${ }^{a}$ Department of Orthopedic Surgery, NYU Hospital for Joint Diseases, 306 E. 15th Street, Suite 1F, New York, NY 10003, USA \\ ${ }^{\mathrm{b}}$ Department of Neurosurgery, University of California San Francisco, 400 Parnassus Ave, San Francisco, CA 94122, USA \\ ${ }^{\mathrm{c}}$ Department of Neurosurgery, University of Virginia Medical Center, Neurosurgery Home, PO Box 800212, Charlottesville, VA 22908, USA \\ ${ }^{\mathrm{d}}$ Department of Orthopedic Surgery, San Diego Center for Spinal Disorders, 4130 La Jolla Village Dr., Suite 300, La Jolla, CA 92037, USA \\ ${ }^{\mathrm{e}}$ Department of Orthopedic Surgery, University of California Davis, 3301 C St., Suite 1500, Sacramento, CA 95816, USA \\ ${ }^{\mathrm{f}}$ Department of Orthopedic Surgery, Oregon Health Sciences University, 3181 SW Sam Jackson Park Rd, Portland, OR, USA \\ ${ }^{\mathrm{g}}$ Department of Orthopedic Surgery, Hospital for Special Surgery, New York, NY, USA \\ ${ }^{\mathrm{h}}$ Laboratory of Biomechanics, Arts et Metier ParisTech, 51, Boulevard de l'hopital, 75013 Paris, France \\ Received 2 July 2013; revised 23 January 2014; accepted 25 January 2014
}

\begin{abstract}
Study Design: Multicenter, prospective, consecutive, surgical case series from the International Spine Study Group.

Objectives: To evaluate the effectiveness of surgical treatment in restoring spinopelvic (SP) alignment.

Summary of Background Data: Pain and disability in the setting of adult spinal deformity have been correlated with global coronal alignment (GCA), sagittal vertical axis (SVA), pelvic incidence/lumbar lordosis mismatch (PI-LL), and pelvic tilt (PT). One of the main goals of surgery for adult spinal deformity is to correct these parameters to restore harmonious SP alignment.

Methods: Inclusion criteria were operative patients (age greater than 18 years) with baseline (BL) and 1-year full-length X-rays. Thoracic and thoracolumbar Cobb angle and previous mentioned parameters were calculated. Each parameter at BL and 1 year was categorized as either pathological or normal. Pathologic limits were: Cobb greater than $30^{\circ}$, GCA greater than $40 \mathrm{~mm}$, SVA greater than $40 \mathrm{~mm}$, PI-LL greater than $10^{\circ}$, and PT greater than $20^{\circ}$. According to thresholds, corrected or worsened alignment groups of patients were identified and overall radiographic effectiveness of procedure was evaluated by combining the results from the coronal and sagittal planes.
\end{abstract}

\begin{abstract}
Author disclosures: BM (none); FS (board membership with Nemaris Inc., consultancy for DePuy, MSD; grants from DePuy, ISSG, SRS; payment for lectures including service on speakers bureaus from DePuy, royalties from MSD, stock/stock options from Nemaris Inc., patent with MSD); CPA (consultancy for DePuy, Stryker, Medtronic; royalties from Aesculap, Lanx; grant from Baxano Surgical; stock/stock options from Baxano Surgical, Doctors Research Group, Visualase; patent for Fish and Richardson, PC); JSS (grant from DePuy Spine to ISSG; consultancy/honorarium from Biomet, DePuy, Medtronic, Globus; fellowship funding and research support from AOSpine; research support from AANS/CNS Joint Spine Section; fellowship support from NREF); DR (none); PVM (royalties from DePuy Spine, Qualified Medical Publishers, Thieme Publishers; honoraria from DePuy Spine and Globus); GMM (personal fees from Nuvasive; grant from Nuvasive; royalties from K2M); JST (none); EK (grants from OREF, Synthes DePuy, AOSpine; personal fees from Synthes DePuy, Stryker, AOSpine, Alphasic); RAH (consultancy for DePuy, Eli Lilly, Medtronic; royalties from DePuy Spine, Seaspine; expert
\end{abstract}

testimony to Evans, Craven, and Lackie, Benson, Bertoldo, Baker, and Carter; travel from Synthes, K2M; stocks from Spine Connect; fellowship support from DePuy Spine, Medtronic, Synthes, OREF); OB (consulting for K2M, DePuy; travel from K2M; research support from K2M; royalties from K2M, DePuy); CIS (grant from ISSG; consultancy for Biomet, Medtronic, Globus, Nuvasive, Stryker; royalties from Biomet, Medtronic; patents for Medtronic, Biomet); WS (none); VL (grant from DePuy Synthes Spine; board membership with Nemaris Inc.; consultancy for MSD; grants from DePuy, ISSG, SRS; payment for lectures including service on speakers bureaus for MSD, DePuy, K2M; stock/stock options for Nemaris Inc).

This work was partially funded via a research grant from DePuy Spine and from the Scoliosis Research Society.

*Corresponding author. Department of Orthopedic Surgery, NYU Hospital for Joint Diseases, 306 E. 15th Street, Suite 1F, New York, NY 1003, USA. Tel.: (646) 794-8646; fax: (646) 602-6926.

E-mail address: virginie.lafage@gmail.com (V. Lafage). 
Results: A total of 161 patients (age, $55 \pm 15$ years) were included. At BL, $80 \%$ of patients had a Cobb angle greater than $30^{\circ}$, $25 \%$ had a GCA greater than $40 \mathrm{~mm}$, and $42 \%$ to $58 \%$ had a pathological sagittal parameter of PI-LL, SVA, and/or PT. Sagittal deformity was corrected in about $50 \%$ of cases for patients with pathological SVA or PI-LL, whereas PT was most commonly worsened (24\%) and least often corrected $(24 \%)$. Only $23 \%$ of patients experienced complete radiographic correction of the deformity.

Conclusions: The frequency of inadequate SP correction was high. Pelvic tilt was the parameter least likely to be well corrected. The high rate of SP alignment failure emphasizes the need for better preoperative planning and intraoperative imaging.

Keywords: Adult spinal deformity; spinopelvic alignment; Surgical treatment; SRS-Schwab classification; Radiographic effectiveness

\section{Introduction}

Although great diversity of deformity patterns exists among patients with adult spinal deformity (ASD), one common objective of any realignment procedure is to restore harmonious spinopelvic alignment in the coronal and sagittal planes.

Several sagittal radiographic parameters define and quantify regional and global spinopelvic alignment: the sagittal vertical axis (SVA), which assesses the global alignment of the spine versus the pelvis; the pelvic incidence minus the lumbar lordosis (PI-LL), which reflects the harmony between lumbar lordosis and the morphologic pelvic incidence; and the pelvic tilt (PT), which characterizes the extent of pelvic compensation for truncal inclination. Recent studies have identified these 3 radiographic parameters as most highly correlated with patient-reported outcomes; accordingly, they were incorporated as the key parameters in the Scoliosis Research Society (SRS) -Schwab classification for ASD [1]. This validated classification [2] defines the threshold of pathological values for the 3 parameters based on correlation with clinical
Coronal alignment

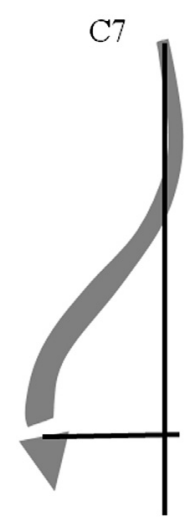

$\mathrm{GCA}<40 \mathrm{~mm}$
Sagittal alignment

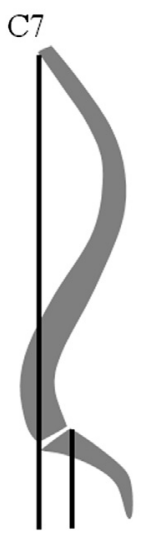

$\mathrm{SVA}<40 \mathrm{~mm}$

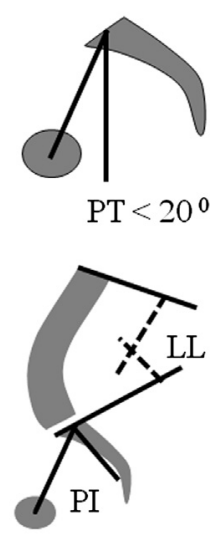

PI-LL $<10^{\circ}$

Fig. 1. Coronal and sagittal radiographic parameters and threshold associated used for the radiographic analysis. GCA, global coronal alignment; SVA, sagittal vertical axis; PT, pelvic tilt; PI, pelvic incidence; LL, lumbar lordosis.

scores: SVA greater than $40 \mathrm{~mm}, \mathrm{PI}-\mathrm{LL}$ greater than $10^{\circ}$, and PT greater than $20^{\circ}$.

The SRS-Schwab classification defines different coronal curve patterns based on Cobb angle measurement and location of the apex of the coronal deformity (thoracic, thoracolumbar/lumbar, or double). Historically, the coronal Cobb angle has been considered the most important parameter for the diagnosis and management strategy of patients with ASD. Glassman et al. [3] and Schwab et al. [1], however, suggested in 2 prospective multicenter studies that the magnitude of coronal deformity is less crucial than the restoration of sagittal alignment in assessing pain and disability, although Glassman et al. [3] demonstrated an association between global coronal alignment (GCA) (an offset of the $\mathrm{C} 7$ plumbline and the sacral line) of greater than $40 \mathrm{~mm}$ in the frontal plane and deterioration in patient outcomes.

From a clinical point of view, interpreting information from several different radiographic parameters in multiple planes can be difficult; an analysis of individual measurements taken independently may help identify the most important parameters to correct.

The objective of this study was to evaluate the effectiveness of surgical treatment in restoring or correcting SVA, PI-LL, PT, coronal Cobb angle, and GCA.

\section{Coronal Curve Types}

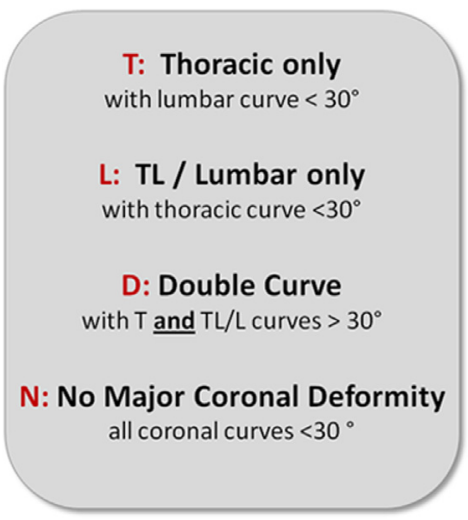

Fig. 2. Scoliosis Research Society-Schwab classification defined by coronal curve type and 3 sagittal spinopelvic modifiers. SVA, sagittal vertical axis; PT, pelvic tilt; PI, pelvic incidence; LL, lumbar lordosis. 
Table 1

Different curve types based on Scoliosis Research Society-Schwab classification for adult spinal deformity.

\begin{tabular}{|c|c|c|c|}
\hline Curve group & Acronym & Coronal criteria & Sagittal criteria \\
\hline Thoracic & $\mathrm{T}$ & Type $\mathrm{T}$ & All modifiers at grade 0 \\
\hline Thoracic/sagittal & TS & Type T & At least 1 modifier at grade + or ++ \\
\hline Thoracolumbar & $\mathrm{L}$ & Type L & All modifiers at grade 0 \\
\hline Thoracolumbar/sagittal & LS & Type L & At least 1 modifier at grade + or ++ \\
\hline Double & $\mathrm{D}$ & Type D & All modifiers at grade 0 \\
\hline Double sagittal & DS & Type D & At least 1 modifier at grade + or ++ \\
\hline Sagittal only & $\mathrm{S}$ & Type N & At least 1 modifier at grade + or ++ \\
\hline Unclassified & $\mathrm{U}$ & Type N & All modifier at grade 0 \\
\hline
\end{tabular}

\section{Materials and Methods}

\section{Patient population and data collection}

This study was a retrospective analysis of a consecutive series of ASD patients enrolled in a prospective multicenter study (10 sites) evaluating operative patients with X-rays at baseline and 1 year after surgery. Subjects were enrolled according to an institutional review board-approved protocol at each site. Inclusion criteria for the database were age greater than 18 years and a radiographic diagnosis of ASD, defined as at least 1 of the following: Cobb angle greater than $20^{\circ}$, SVA greater than $50 \mathrm{~mm}$, PT greater than $25^{\circ}$, and thoracic kyphosis greater than $60^{\circ}$. Exclusion criteria were the presence of inflammatory arthritis, tumors, or neuromuscular disease. Demographic and medical history data were collected. Standing anteroposterior and lateral spine radiographs were analyzed at baseline and 1 year after surgery using validated software $[4,5]$ (Spineview; Laboratory of Biomechanics Arts et Metiers ParisTech, Paris, France) to measure thoracic (T) and thoracolumbar (L) coronal Cobb angles, GCA, SVA, PI-LL, and PT (Fig. 1). For the present study, patients without complete sets of X-rays at baseline and 1 year after the surgery were excluded.

\section{Baseline classification}

Each patient was individually classified according to the SRS-Schwab classification of ASD [A,B] (Fig. 2), which distinguishes 8 groups based on deformity pattern (Table 1).

Table 2

Treatment efficiency groups for Cobb angle, global coronal alignment, sagittal vertical axis, pelvic incidence/lumbar lordosis mismatch, and pelvic tilt.

\begin{tabular}{lll}
\hline $\begin{array}{l}\text { Treatment efficiency } \\
\text { group }\end{array}$ & $\begin{array}{l}\text { Meet deformity } \\
\text { threshold at } \\
\text { baseline? }\end{array}$ & $\begin{array}{l}\text { Meet deformity } \\
\text { threshold at 1 year } \\
\text { postoperatively? }\end{array}$ \\
\hline Consistently normal & No & No \\
Radiographic deterioration & No & Yes \\
Persistent deformity & Yes & Yes \\
Radiographic correction & Yes & No \\
\hline
\end{tabular}

\section{Surgical correction of individual parameters}

Each radiographic parameter was analyzed at baseline and 1 year postoperatively to identify whether it met the following deformity thresholds: Cobb angle greater than $30^{\circ}$, GCA greater than $40 \mathrm{~mm}$, SVA greater than $40 \mathrm{~mm}$, PI-LL greater than $10^{\circ}$, and PT greater than $20^{\circ}$. The researchers used the comparison between baseline and 1 year to individually categorize patients into one of the following treatment efficiency groups for each parameter (Table 2): "consistently normal," "radiographic deterioration," "persistent deformity," and "radiographic correction."

\section{Overall effectiveness}

At 1 year, the overall radiographic effectiveness of the realignment procedure was evaluated individually by combining the results from the coronal and sagittal planes to make the following 4 groups: 1) no deformity: patients who did not meet the deformity threshold for any of the 5 parameters; 2) coronal deformity: patients who met only coronal deformity threshold(s) (Cobb angle and/or GCA); 3) sagittal deformity: patients who met only sagittal deformity threshold(s) (SVA, PT, and/or PI-LL); and 4) combined deformity: patients who met at least 1 coronal and 1 sagittal deformity threshold.

\section{Statistical analysis}

The authors evaluated differences in demographic data between deformity classification groups at baseline using analysis of variance. A significance threshold was established at $\mathrm{p}<.05$. At baseline, the distribution of patients with sagittal deformity was expressed for the different combinations of sagittal parameter. At baseline and 1 year, the proportion of patients in the entire sample with a deformity was calculated for each parameter independently. Then, for patients with deformity at baseline, the fraction of patients in the radiographic correction and persistent deformity groups was calculated by comparison with 1-year data for each parameter. Similarly, for patients without deformity at baseline, the fraction of patients in the radiographic deterioration and consistently normal groups was established for each parameter. Finally, the proportion of patients in each postoperative classification group was 
Table 3

Number of patients enrolled, with adequate baseline radiographs, with adequate baseline radiographs and 1-year follow-up, and with adequate baseline and 1-year radiographs, by site.

\begin{tabular}{|c|c|c|c|c|c|c|c|c|c|c|c|}
\hline \multirow[t]{2}{*}{ Number of patients } & \multirow[t]{2}{*}{ Total } & \multicolumn{10}{|c|}{ Site } \\
\hline & & A & $\mathrm{B}$ & $\mathrm{C}$ & $\mathrm{D}$ & $\mathrm{E}$ & $\mathrm{F}$ & G & $\mathrm{H}$ & I & $\mathbf{J}$ \\
\hline Enrolled & 315 & 59 & 14 & 51 & 6 & 33 & 25 & 15 & 15 & 58 & 39 \\
\hline Enrolled, adequate baseline radiographs, and 1-year follow-up & 215 & 55 & 10 & 42 & 4 & 20 & 10 & 15 & 8 & 21 & 30 \\
\hline Enroll, adequate baseline, and 1-year radiographs & 161 & 51 & 6 & 31 & 4 & 16 & 9 & 10 & 7 & 3 & 24 \\
\hline
\end{tabular}

calculated for the entire population and after stratifying by curve type.

\section{Results}

\section{Enrollment}

A total of 316 surgical patients were enrolled in this study between 2008 and 2011; 252 had adequate baseline radiographs and 215 patients had adequate baseline radiographs and 1-year follow-up (Table 3). Of those 215 patients, 161 had adequate baseline and 1-year radiographs and were the only ones included in this study.

\section{Demographics and curve type}

This study included 161 ASD patients (24 males and 137 females) with a mean age of $55 \pm 15$ years (Table 4 ). Eighty percent of the patients had a coronal Cobb angle greater than $30^{\circ}$; patients with thoracic curve $(13 \%)$ were less common than patients with thoracolumbar/lumbar curve $(34 \%)$ or double curve $(33 \%)$. Analysis of sagittal spinopelvic parameters revealed that $71 \%$ of patients had a sagittal deformity (SVA, PI-LL, or PT meeting deformity thresholds), 54\% of whom had both coronal and sagittal deformity (thoracic/sagittal [TS], thoracolumbar/sagittal [LS], and double sagittal [DS]) and $17 \%$ of whom had a pure sagittal deformity (S). A total of 5 patients (3\%) were unclassifiable because of the difference between the inclusion criteria for the database (coronal Cobb angle greater than $20^{\circ}$ ) and the SRS-Schwab classification threshold for deformity in the coronal plane (Cobb angle greater than $30^{\circ}$ ). These patients were removed from the analysis of treatment efficiency.

Patients with pure thoracic coronal curves (T) were significantly younger $(31 \pm 12$ years $)$ than those with other curve types $(\mathrm{p}<.05)$. Within the group of patients with thoracolumbar/lumbar coronal curves (L and LS), patients with sagittal deformities (LS: age, $63 \pm 8$ years; body mass index [BMI], $28 \pm 8$ ) were older and had a greater BMI than patients without sagittal deformity (L: age, $47 \pm 13$ years; BMI, $23 \pm 3)(\mathrm{p}<.05)$. Patients with only sagittal deformity (S: age, $67 \pm 13$ years) were older than any of the groups with only coronal deformities (T, L, and D) $(p<.05)$. A total of $37 \%$ of patients had a history of spine surgery. The rate of history of spine surgery varied between $0 \%$ and $60 \%$, depending of the type of curve. Patients with sagittal deformity (with or without coronal deformity) were more likely to have had prior surgery than patients without sagittal deformity.

\section{Sagittal deformity: distribution of sagittal parameters combinations}

At baseline, the most frequent sagittal deformity (44\%) was a combination of the 3 parameters (SVA, PI-LL, and PT) (Table 5). The second most frequent sagittal deformity was defined by only a pelvic retroversion (20\%). Three percent of patients with sagittal deformity had only a mismatch between the PI and LL.

\section{Review of individual radiographic parameters}

Figure 3 shows radiographic treatment effectiveness for the different parameters. Table 6 expresses the distribution of patients meeting radiographic deformity thresholds at baseline and 1 year after surgery. Table 7 expresses the percentage of patients who were persistently deformed, out of the population with deformity at baseline; and Table 7 expresses the percentage of patient who had deteriorated radiographically, out of the population without deformity at baseline.

Table 4

Demographic data and prior surgery, by type of curve.

\begin{tabular}{|c|c|c|c|c|c|c|c|c|c|}
\hline & $\mathrm{U}$ & $\mathrm{T}$ & $\mathrm{L}$ & $\mathrm{D}$ & TS & LS & DS & $\mathrm{S}$ & Total \\
\hline Total sample (\% [n]) & $3 \%(5)$ & $7 \%(11)$ & $10 \%(16)$ & $9 \%(16)$ & $6 \%(10)$ & $24 \%(38)$ & $24 \%(37)$ & $17 \%(28)$ & $100 \%(161)$ \\
\hline Age & $52 \pm 14$ & $31 \pm 12$ & $47 \pm 13$ & $47 \pm 13$ & $47 \pm 16$ & $63 \pm 8$ & $55 \pm 12$ & $67 \pm 13$ & $55 \pm 15$ \\
\hline Body mass index & $24 \pm 8$ & $22 \pm 5$ & $23 \pm 3$ & $25 \pm 4$ & $31 \pm 15$ & $28 \pm 8$ & $27 \pm 7$ & $30 \pm 7$ & $27 \pm 8$ \\
\hline Prior surgery (\%) & 60 & 0 & 19 & 6 & 60 & 55 & 24 & 57 & 37 \\
\hline
\end{tabular}

U, unclassified; T, thoracic; TL, thoracic sagittal; L, thoracolumbar; LS, thoracolumbar sagittal; D, double; DS, double sagittal; S, sagittal. 
Table 5

At baseline, distribution of patients with sagittal deformity for different combinations of sagittal parameters.

\begin{tabular}{lllllll}
\hline \multicolumn{2}{l}{ Distribution of patients with sagittal deformity $(\%[\mathrm{n}])$} \\
\hline SVA & PI-LL & PT & SVA+PI-LL & SVA+PT & PI-LL+PT & SVA+PI-LL+PT \\
\hline $12[14]$ & $3[3]$ & $20[23]$ & $2[2]$ & $8[7]$ & $12[13]$ & $44[50]$ \\
\hline
\end{tabular}

SVA, sagittal vertical axis; PI-LL, mismatch between pelvic incidence and lumbar lordosis; PT, pelvic tilt.

\section{Coronal Cobb angle}

At baseline, coronal Cobb angle greater than $30^{\circ}$ was the most common deformity ( $80 \%$ of the total population). The Cobb angle was persistently present in $30 \%$ of those patients, and so was corrected in $70 \%$, which made it also the most consistently corrected parameter. Cobb angle was the parameter that deteriorated least frequently: Only 3 patients (9\%) had deterioration; all had a preoperative Cobb angle close to $30^{\circ}$, and deterioration was between $3^{\circ}$ and $7^{\circ}$. Postoperatively, $26 \%$ of patients had a Cobb angle greater than $30^{\circ}$.

\section{Global coronal alignment}

At baseline, GCA was the least frequent deformity (25\%; 41 patients); $93 \%$ of these patients (38) had a thoracolumbar curve (L, LS, double curve, or DS). The GCA was corrected in $54 \%$ of those patients. However, GCA was also one of the most likely deteriorated parameters, because $18 \%$ of patients with a normal alignment at baseline met the threshold for deformity 1 year after surgery. This led to an overall rate of postoperative coronal malalignment of $25 \%$, the same as the preoperative deformity rate.

\section{Radiographic treatment efficiency by parameters}

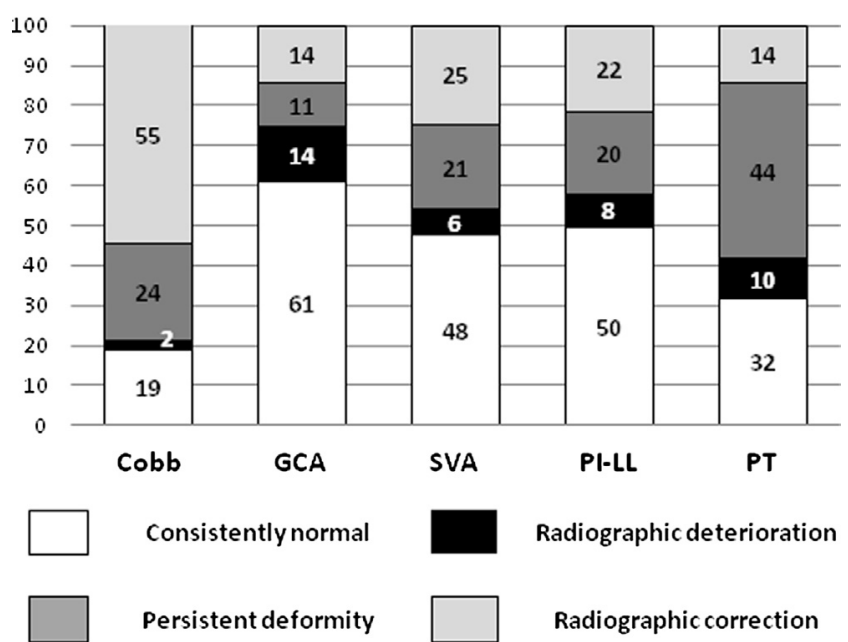

Fig. 3. Radiographic treatment efficiency by parameters (in \%). GCA: global coronal alignement, SVA, sagittal vertical axis; PI-LL, pelvic incidence-lumbar lordosis; PT, pelvic tilt.

\section{Sagittal vertical axis}

At baseline, $46 \%$ of the patients had an SVA that met the deformity threshold. A total of $54 \%$ of these patients were radiographically corrected, whereas $11 \%$ of patients with a normal preoperative SVA deteriorated. Postoperatively, a total of $27 \%$ of the patients had an SVA meeting the deformity threshold.

\section{Pelvic incidence/lumbar lordosis mismatch}

At baseline, $42 \%$ of the patients had a PI-LL value that met deformity thresholds. $51 \%$ of these subjects were radiographically corrected, whereas $14 \%$ of patients with a normal preoperative PI-LL deteriorated. Postoperatively, $29 \%$ of patients had PI-LL that met the deformity threshold.

\section{Pelvic tilt}

At baseline, $58 \%$ of patients had a PT meeting the deformity threshold (ie, substantial pelvic retroversion); this represented the most frequent deformity among the sagittal parameters. Only $24 \%$ of these patients were radiographically corrected, and $24 \%$ with a normal baseline PT deteriorated postoperatively. Overall, 54\% of patients had a PT that met the deformity threshold at 1 year.

\section{Overall results at 1 year}

Table 8 lists the overall deformity distribution at 1 year. A total of $23 \%$ of patients had no deformity in either the coronal or sagittal plane, $35 \%$ had a deformity only in the sagittal plane, $14 \%$ only in the coronal plane, and $27 \%$ in both the coronal and sagittal planes. Patients with baseline deformity in the coronal plane only (T, L, or D) were more

Table 6

Distribution of patients who met radiographic deformity thresholds at baseline and 1 year after surgery, for different parameters.

\begin{tabular}{llr}
\hline & \multicolumn{2}{l}{ Distribution of patients $(\%[\mathrm{n}])$} \\
\cline { 2 - 3 } & Baseline & 1 year \\
\hline Cobb angle & $80(128)$ & $26(42)$ \\
Global coronal alignment & $25(41)$ & $25(40)$ \\
Sagittal vertical axis & $46(74)$ & $27(44)$ \\
Pelvic incidence and lumbar & $42(68)$ & $29(46)$ \\
$\quad$ lordosis mismatch & $58(94)$ & $54(87)$ \\
Pelvic tilt & & \\
\hline
\end{tabular}


Table 7

Patients persistently deformed, of population with deformity at baseline.

\begin{tabular}{llll}
\hline Patients at 1 year $(\%[\mathrm{n}])$ & & \\
\hline Cobb angle & $\begin{array}{l}\text { Global coronal } \\
\text { alignment }\end{array}$ & $\begin{array}{l}\text { Sagittal } \\
\text { vertical axis }\end{array}$ & $\begin{array}{l}\text { Pelvic incidence } \\
\text { and lumbar } \\
\text { lordosis mismatch }\end{array}$ \\
\hline $30[39]$ & $44[18]$ & $46[34]$ & $49[33]$ \\
$9[3]$ & $18[22]$ & $11[10]$ & $14[13]$ \\
\hline
\end{tabular}

likely to have complete resolution of the deformity, especially patients with lumbar curves $(75 \%)$. For patients presenting with coronal and sagittal deformity at baseline, this sagittal deformity was not corrected for $68 \%$ (DS) to $86 \%$ (S), depending on the type of curve.

\section{Discussion}

Adult spinal deformity encompasses a broad range of radiographic patterns, which makes it challenging to dissociate the intrinsic parameters of the deformity from those related to compensatory mechanisms. Recent reports have brought to light the difficulty in restoring spinopelvic alignment after 3-column osteotomies [2,6]. One common limitation to these studies is that they tend to focus on a single parameter and are often limited to a single plane (coronal or sagittal).

The objective of this study was to evaluate the ability of surgical treatment to radiographically restore spinopelvic alignment while taking into account the type of deformity. With the exception of the coronal Cobb angle, all radiographic parameters were chosen based on their reported clinical relevance (ie, correlation with patient-reported outcomes), as demonstrated in large cohorts of patients representing the full spectrum of ASD $[1,3]$. Several studies have shown correlation between clinical scores and coronal or sagittal global alignment (GCA/SVA) $[1,3,6,7,8]$. In an exception to these results, Sanchez-Mariscal et al. [9] demonstrated only a low correlation between clinical scores after primary surgery and sagittal malalignment (PT and SVA) in 59 ASD patients. Based on multivariate analysis, the only significant predictor of disability was PT. However, the extent of deformity (ie, whether the patient had sagittal imbalance) and the effect of the surgery were not taken into account. To avoid the former problem, the current study compared radiographic parameters to thresholds of clinical relevance $[1,3,6]$.

However, the current method was limited in that it did not account for the absolute magnitude of surgical correction with regard to the severity of deformity at baseline. As such, a patient with a severe baseline deformity who had significant surgical correction would still be considered undercorrected if he or she did not reach the deformity threshold. The decision to overlook this issue was motivated by 2 reasons. First, the thresholds were defined by databases that included operative and nonoperative patients with and without previous surgery. Therefore, patients with severe baseline deformity and significant restoration were incorporated into the calculation of thresholds. Second, the objective of this study was to analyze the radiographic effectiveness of the surgery, not the clinical effect.

\section{Analysis by parameter}

The results illustrate that a large number of patients are insufficiently corrected and that deterioration in alignment is not a negligible phenomenon; notably, for coronal malalignment (GCA), the number of patients who were corrected was similar to that of patients who deteriorated (Fig. 3). Whereas the clinical impact of the Cobb angle remains controversial, scoliosis is nevertheless the most common deformity in ASD surgical patients $(80 \%$ in this database). In this study, it was also the parameter with the highest rate of correction. This may reflect a historical bias to predominantly treating the most obvious aspect of ASD, even though sagittal parameters have been shown to be more influential on clinical scores $[8,10,11]$.

Each sagittal parameter represents a different component of an individual's deformity. Whereas in $44 \%$ of the cases the sagittal deformity was a combination of the 3 sagittal parameters, it also appears that great variability of combinations exist between patients. The PI-LL represents a regional disharmony between PI, a morphologic parameter, and LL. The surgeon can directly affect this parameter. The considerable rate of inadequate PI-LL correction ( $48 \%$ in the total sample) may illustrate insufficient consideration of this important relationship. Pelvic tilt was the parameter that most often deteriorated, as well as the one least often corrected. Pelvic tilt represents a pelvic compensatory mechanism. Although the surgeon cannot directly modify this parameter, several models of PT prediction have been developed [12], and complete correction of structural sagittal deformity should obviate the need for pelvic compensation. Results from this study illustrate the gap between the scientific community and clinical practice. The combination of the 3 sagittal parameters revealed that sagittal deformity was present in $71 \%$ of patients preoperatively and $62 \%$ postoperatively, again perhaps indicating a lack of focus on sagittal imbalance during surgery.

\section{Analysis by curve type}

The diversity of curve types in ASD patients has often been noted, rendering the analysis of ASD patients as a 
Table 8

Postoperative categorization.

\begin{tabular}{|c|c|c|c|c|c|c|c|c|}
\hline Type of curve & Thoracic & Thoracolumbar & Double & Thoracic sagittal & $\begin{array}{l}\text { Thoracolumbar } \\
\text { sagittal }\end{array}$ & $\begin{array}{l}\text { Double } \\
\text { sagittal }\end{array}$ & Sagittal & Total \\
\hline No deformity & $55[6]$ & $75(9)$ & $38(6)$ & $20(2)$ & $5(2)$ & $16(6)$ & $14(4)$ & $23(37)$ \\
\hline Coronal deformity & $18(2)$ & $13(5)$ & $25(4)$ & $10(1)$ & $13(5)$ & $16(6)$ & 0 & $14(23)$ \\
\hline Sagittal deformity & $18(2)$ & $13(2)$ & $25(4)$ & $50(5)$ & 45 (14) & $32(11)$ & $75(17)$ & $35(57)$ \\
\hline Combined deformity & $9(1)$ & 0 & $13(2)$ & $20(2)$ & 37 (17) & $35(14)$ & $11(7)$ & $27(44)$ \\
\hline
\end{tabular}

Data are shown as patients (\% [n]) falling into the following groups: no deformity (no parameters meeting deformity thresholds), coronal deformity (coronal Cobb angle and/or global coronal alignment meeting thresholds), sagittal deformity (sagittal vertical axis, pelvic tilt, and/or pelvic incidence and lumbar lordosis mismatch meeting thresholds), and combined deformity (at least 1 coronal and 1 sagittal parameter meeting thresholds) groups by Scoliosis Research Society-Schwab curve type.

single group inadequate. In contrast to adolescent idiopathic scoliosis $[13,14]$, there has been limited consensus regarding the classification of ASD [15]. The researchers' choice was to use the recently described SRS-Schwab classification of ASD because of its simplicity (only 4 radiographic parameters must be evaluated) and clinical relevance.

Only $23 \%$ of patients experienced complete radiographic correction of the deformity. Highly varying rates of correction were observed between the different SRS-Schwab curve types. These differences may relate to differences in overall complexity between curve types and variability in baseline severity of deformity. Although patients with baseline deformity in the coronal plane only (T, L, or D) had a greater chance of achieving complete correction than patients with sagittal deformity, there was still substantial variability in the likelihood of correction between coronal groups. In particular, double curves appear to be much more difficult to completely correct than single curves. These results may help identify the risks of radiographic malalignment or deterioration that vary between SRS-Schwab curve types.

This study represents a detailed analysis of surgical realignment outcomes across ASD patterns. The large numbers of patients who were insufficiently corrected and who deteriorated highlight the need to continue research to determine which parameters are most important, and to develop surgical procedures that consistently improve radiographic outcomes. Although this study did not identify factors leading to suboptimal radiographic outcome, several aspects of surgical treatment warrant scrutiny. In addition to appropriate surgical planning, it appears essential to develop better intraoperative tools to allow feedback to the surgeon so that operative intervention aligns with planning goals. Longer follow-up analysis is important to assess variations in compensatory parameters (notably PT), as well as alignment of nonfused portions of the spine. Furthermore, correlation between radiographic correction and clinical benefit requires further analysis.

\section{References}

[1] Schwab FJ, Blondel B, Bess S, et al. Radiographic spino-pelvic parameters and disability in the setting of adult spinal deformity: a prospective multicenter analysis. Spine (Phila Pa 1976) 2013;38: E803-12.

[2] Schwab FJ, Patel A, Shaffrey CI, et al. Sagittal realignment failures following pedicle subtraction osteotomy surgery: are we doing enough? J Neurosurg Spine 2012;16:539-46.

[3] Glassman SD, Berven S, Bridwell K, et al. Correlation of radiographic parameters and clinical symptoms in adult scoliosis. Spine (Phila Pa 1976) 2005:30:682-8.

[4] Champain S, Benchikh K, Nogier A, et al. Validation of new clinical quantitative analysis software applicable in spine orthopaedic studies. Eur Spine J 2006;15:982-91.

[5] Rillardon L, Levassor N, Guigui P, et al. [Validation of a tool to measure pelvic and spinal parameters of sagittal balance]. Rev Chir Orthop Reparatrice Appar Mot 2003;89:218-27.

[6] Smith JS, Klineberg E, Schwab F, et al. Change in classification grade by the SRS-Schwab adult spinal deformity classification predicts impact on health-related quality of life measures: prospective analysis of operative and non-operative treatment. Spine (Phila $\mathrm{Pa}$ 1976) 2013;38:1663-71.

[7] Lafage V, Schwab F, Patel A, et al. Pelvic tilt and truncal inclination: two key radiographic parameters in the setting of adults with spinal deformity. Spine (Phila Pa 1976) 2009;34: E599-606.

[8] Blondel B, Schwab F, Ungar B, et al. Impact of the magnitude and percentage global sagittal plane correction on health related quality of life at 2 years follow up. Eur Spine $J$ 2012;21. S278-S.

[9] Sanchez-Mariscal F, Gomez-Rice A, Izquierdo E, et al. Correlation of radiographic and functional measurements in patients who underwent primary scoliosis surgery in adult age. Spine (Phila Pa 1976) 2012;37:592-8.

[10] Blondel B, Lafage V, Schwab F, et al. Reciprocal sagittal alignment changes after posterior fusion in the setting of adolescent idiopathic scoliosis. Eur Spine J 2012;21:1964-71.

[11] Ploumis A, Liu H, Mehbod AA, et al. A correlation of radiographic and functional measurements in adult degenerative scoliosis. Spine (Phila Pa 1976) 2009:34:1581-4.

[12] Lafage V, Schwab F, Vira S, et al. Spino-pelvic parameters after surgery can be predicted: a preliminary formula and validation of standing alignment. Spine (Phila Pa 1976) 2011;36: 1037-45.

[13] Lenke LG, Betz RR, Harms J, et al. Adolescent idiopathic scoliosis: a new classification to determine extent of spinal arthrodesis. $J$ Bone Joint Surg Am 2001;83:1169-81.

[14] Lenke LG. The Lenke classification system of operative adolescent idiopathic scoliosis. Neurosurg Clin N Am 2007;18: 199-206.

[15] Smith A, O'Sullivan P, Straker L. Classification of sagittal thoracolumbo-pelvic alignment of the adolescent spine in standing and its relationship to low back pain. Spine (Phila Pa 1976) 2008;33: $2101-7$. 